\title{
Is there really misuse and abuse of dabigatran?
}

\section{A brief commentary on the RE-LY study}

ppropriate and optimal anticoagulation for the increasing number of Australians with nonvalvular atrial fibrillation (AF) remains a challenge. If achieved, it would substantially reduce the burden of disabling and fatal AF-related stroke.

Four large randomised controlled trials (RCTs) have reported that the direct thrombin inhibitor, dabigatran etexilate, and the direct activated factor $\mathrm{X}(\mathrm{Xa})$ inhibitors, rivaroxaban and apixaban, are at least as efficacious and safe as warfarin, and apixaban is superior to aspirin, in a broad range of individuals with non-valvular $\mathrm{AF}^{1-5}$ On the basis of these results, regulators have approved dabigatran in more than 75 countries, including Australia, and guidelines suggest that the new oral anticoagulants are preferable to warfarin for most patients with non-valvular AF. ${ }^{6-9}$

\section{Patient selection in the RE-LY trial}

The RE-LY (Randomized Evaluation of Long-Term Anticoagulant Therapy) trial of dabigatran versus warfarin included patients with all degrees of risk of stroke and systemic embolism. ${ }^{9}$ If the trial had excluded participants with a low risk, ie, a $\mathrm{CHADS}_{2}$ score of 1 (congestive heart failure, hypertension, age $\geqslant 75$ years, diabetes, 1 point each; prior stroke or transient ischaemic attack, 2 points), clinicians would not now know that these patients derive benefit from dabigatran compared with warfarin.

\section{Quality of anticoagulation control}

RE-LY trial participants who were assigned warfarin had a median time in therapeutic range (TTR) of $67 \%$. This may have led to an underestimate of the benefits of dabigatran compared with warfarin in community practice, where the median TTR for patients taking warfarin is rarely this high.

\section{Benefits of dabigatran}

Dabigatran (150 mg twice daily) compared with warfarin produced reductions in ischaemic stroke (one-third) and haemorrhagic stroke (one-half) that were statistically significant and clinically important. The reduction in stroke with dabigatran was also evident in the very elderly, participants with renal impairment, participants with previous myocardial infarction (MI) or stroke, and in the presence and absence of aspirin.

\section{Safety of dabigatran}

Both doses (110 mg or $150 \mathrm{mg}$ twice a day) of dabigatran were associated with significantly lower life-threatening
John W Eikelboom MB BS, MSC, Associate Professor

Graeme J Hankey MD, FRACP, FRCP Clinical Professor ${ }^{2}$

Department of Medicine, McMaster University, Hamilton, Ontario, Canada. 2 School of Medicine and Pharmacology, University of Western Australia, Perth, WA.

eikelbj@mcmaster.ca

doi: 10.5694/mjal2.11642

the new oral anticoagulants are preferable to warfarin for most patients with nonvalvular atrial fibrillation

Perspective p 356 and fatal bleeding than warfarin. Among participants aged $\geqslant 75$ years, extracranial bleeding risk was similar or higher with both doses of dabigatran compared with warfarin, whereas intracranial bleeding risk was lower with both doses of dabigatran. ${ }^{10}$ In participants aged $<75$ years, both doses of dabigatran were associated with lower risks of both intracranial and extracranial bleeding than warfarin.

Participants who were taking dabigatran also had lower rates of bleeding if they required urgent or emergency surgery than those taking warfarin, despite access to vitamin $\mathrm{K}$ and clotting factors that could pharmacologically reverse the anticoagulant effect of warfarin. ${ }^{11}$ Although there is no specific antidote for dabigatran, the case-fatality rate of intracranial haemorrhage was not significantly different in participants assigned dabigatran or warfarin. ${ }^{12}$

The absolute increase in MI with dabigatran compared with warfarin was $0.14 \%-0.17 \%$ per year. This was outweighed by a $0.6 \%$ per year reduction in stroke and systemic embolism. ${ }^{13}$ Adding aspirin to dabigatran did not protect against any increased risk of MI, but increased bleeding.

\section{Real world experience with dabigatran}

Recent postmarketing surveillance by the European Medicines Agency and the United States Food and Drug Administration (FDA) found no evidence of excess serious bleeding with dabigatran compared with warfarin. ${ }^{14,15}$

We have a continued responsibility to ensure that the favourable effects of new anticoagulants compared with warfarin demonstrated in RCTs are translated into clinical practice. Ongoing Phase IV safety surveillance, economic analysis, and doctor and patient education are key to this process.

Meanwhile, optimal safety and effectiveness of the new oral anticoagulants in routine clinical practice demand appropriate selection of patients (eg, estimated glomerular filtration rate $\geqslant 30 \mathrm{~mL} / \mathrm{min}$ ) and dose, a high level of adherence, regular monitoring of renal function (which may deteriorate in at-risk patients) and appropriate periprocedural management of anticoagulation interruption for invasive procedures. As treatment with a new oral anticoagulant is not suitable for all patients, warfarin will retain an important role in the management of patients who can maintain excellent anticoagulant control, as well as those with severe renal impairment and other contraindications to the new oral anticoagulants.

Competing interests: John Eikelboom was a member of the RE-LY Steering Committee and has received honoraria and grant support from the manufacturers of new oral anticoagulants including Bayer, Boehringer Ingelheim, Bristol-Myers Squibb, Daiichi Sankyo, Janssen and Pfizer. Graeme Hankey has received honoraria for serving on the executive steering committees of the ROCKET-AF trial (Johnson and Johnson), the AMADEUS and BOREALIS trials (Sanofi), and the stroke outcome adjudication committees of the RE-LY trial and AVERROES trial, and has received honoraria from Bayer, Boehringer Ingelheim, Bristol-Myers Squibb and Pfizer for speaking at sponsored scientific symposia and consulting on advisory boards.

Provenance: Commissioned; externally peer reviewed. 
1 Connolly SJ, Ezekowitz MD, Yusuf S, et al. Dabigatran versus warfarin in patients with atrial fibrillation. NEngl J Med 2009; 361: 1139-1151.

2 Patel MR, Mahaffey KW, Garg J, et al. Rivaroxaban versus warfarin in nonvalvular atrial fibrillation. N Engl J Med 2011; 365: 883-891.

3 Granger CB, Alexander JH, McMurray JJ, et al. Apixaban versus warfarin in patients with atrial fibrillation. NEngl J Med 2011; 365: 981-992.

4 Connolly SJ, Eikelboom J, Joyner C, et al. Apixaban in patients with atrial fibrillation. N Engl J Med 2011; 364: 806-817.

5 Connolly SJ, Ezekowitz MD, Yusuf S, et al. Newly identified events in the RE-LY trial. NEngl J Med 2010; 363: 1875-1876.

6 You JJ, Singer DE, Howard PA, et al. Antithrombotic therapy for atrial fibrillation: Antithrombotic therapy and prevention of thrombosis, 9th ed: American College of Chest Physicians Evidence-Based Clinical Practice Guidelines. Chest 2012; 141 (2 Suppl): e531S-e575S.

7 Skanes AC, Healey JS, Cairns JA, et al. Focused 2012 update of the Canadian Cardiovascular Society atrial fibrillation guidelines: recommendations for stroke prevention and rate/rhythm control. Can J Cardiol 2012; 28: 125-136.

8 Furie KL, Goldstein LB, Albers GW, et al. Oral antithrombotic agents for the prevention of stroke in nonvalvular atrial fibrillation: a science advisory for healthcare professionals from the American Heart Association/American Stroke Association. Stroke 2012; 43: 3442-3453.

9 Camm AJ, Lip GY, De CR, et al. 2012 focused update of the ESC Guidelines for the management of atrial fibrillation: An update of the 2010 ESC Guidelines for the management of atrial fibrillation. Developed with the special contribution of the European Heart Rhythm Association. Eur Heart J 2012; 33 : 2719-2747.

10 Eikelboom JW, Wallentin L, Connolly SJ, et al. Risk of bleeding with 2 doses of dabigatran compared with warfarin in older and younger patients with atrial fibrillation: an analysis of the randomized evaluation of long-term anticoagulant therapy (RE-LY) trial. Circulation 2011; 123: 2363-2372.

11 Healey JS, Eikelboom J, Douketis J, et al. Periprocedural bleeding and thromboembolic events with dabigatran compared with warfarin: results from the Randomized Evaluation of Long-Term Anticoagulation Therapy (RE-LY) randomized trial. Circulation 2012; 126: 343-348.

12 Hart RG, Diener HC, Yang S, et al. Intracranial hemorrhage in atrial fibrillation patients during anticoagulation with warfarin or dabigatran: the RE-LY trial. Stroke 2012; 43: 1511-1517.

13 Hohnloser SH, Oldgren J, Yang S, et al. Myocardial ischemic events in patients with atrial fibrillation treated with dabigatran or warfarin in the RE-LY trial. Circulation 2012; 125: 669-676.

14 European Medicines Agency. Opinions on annual re-assessments, renewals of marketing authorisations and accelerated assessment procedures. Adopted at the CHMP meeting of 15-18 October 2012. http://www.ema.europa.eu/docs/ en_GB/document_library/Other/2012/10/WC500134406.pdf (accessed Feb 2013).

15 Food and Drug Administration. FDA drug safety communication: update on the risk for serious bleeding events with the anticoagulant Pradaxa (dabigatran). http://www.fda.gov/Drugs/DrugSafety/ucm326580.htm (accessed Feb 2013).

\section{Stamps of greatness}

\section{Theodore Kocher (1841-1917)}

THEODOR KOCHER was born in Bern, Switzerland, on 25 August 1841. After graduating in medicine from the University of Bern in 1865, he worked with people like Bilroth, Lister, Pasteur and Langenbeck for a year, before returning to become an assistant at the University of Berne clinic.

In 1872 he was appointed to the chair of surgery, a position he held until his death. Although a general surgeon, Kocher pioneered many new fields and ultimately achieved world renown, especially in thyroid surgery. However, he was equally proficient in gynaecological, brain and abdominal surgery.

Kocher was noted for his method of reducing dislocations of the shoulder joint (1870), his contributions to treating hernia and osteomyelitis, his operations for an artificial anus, his hydrodynamic theory of the effect of gunshot wounds and, especially, for his work on the thyroid gland.

He was the first to excise the thyroid for goitre (1878), and he performed this difficult operation over 2000 times with a patient mortality of just $4.5 \%$. In 1883 he published his description of cachexia strumipriva, which he had found in 30 of his first 100 thyroidectomies.

Kocher also applied experimental surgery to the physiology of the brain and spinal cord. In 1912 he conceived the idea of injecting sterilised coagulant (derived by Fonio from blood platelets) to accelerate coagulation in internal haemorrhage.

During the Franco-Prussian War of 1870 he lectured on military surgery and in 1877 he became the first president of the Military Pension Commission. In 1895 he investigated gunshot wounds from small calibre bullets.

Kocher was a precise and skilful operator, who obtained a complete clinical history on his patients before operating and who maintained a completely aseptic operating environment. He was among the first to adopt Lister's antiseptic techniques.
Professor Harvey Cushing, in his telling address before the International Congress in London (1913) said:

"... the accurate and detailed methods, in the use of which Kocher and Halstead were for so long the notable examples, have spread into all clinics, at least into those clinics where you or I would wish to entrust ourselves for operation. Observers no longer expect to be thrilled in an operating room; the spectacular public performances of the past, no longer condoned, are replaced by the quiet, rather tedious procedures, which few beyond the operator, his assistants and the immediate bystanders can profitably see. The patient on the table, like a passenger in a car, runs great risks if he has a loquacious driver or one who takes close corners, exceeds the speed limit, or rides to admiration" (BMJ 1913).

Kocher was instrumental in establishing the chair of bacterioiogy in Bern. He was elected to the German Surgical Society in 1902, and went on to become its president. In 1908 he became the president of the International Surgical Society and in 1909 he received the Nobel Prize in Medicine for his work in thyroid surgery.

Kocher's textbook on surgery, published in 1892, was translated into many languages. He is remembered today for the "Kocher clamp" for the compression of bleeding tissues; for various surgical procedures for the ankle joint, thyroid and tongue; for the "Kocher incision" in gallbladder surgery and for the "Kocher manoeuvre" for treating a dislocated shoulder.

Active to the end of his life, Kocher died on 27 July 1917 in Bern and was postally honoured by his country in 1967 as a surgeon and Nobel Prize winner. 